\title{
Prevalence of Microalbuminuria and Associated Factors Among Type 2 Diabetes Mellitus Patients in Jigjiga Town Public Hospitals, Somali Regional State, Ethiopia, 2020
}

Abdilahi Ibrahim Muse

Jigjiga University

Mohamed Omar Osman

Jigjiga University

Girma Tadesse Wedajo

Jigjiga University

Kalkidan Hassen Abate

Jimma University

Ahmed Mohammed Ibrahim

Jigjiga University

Ramadan Budul Yusuf

Jigjiga University

Abdulahi Siraj Abdi

Jigjiga University

Sied Abdi Usman

Jigjiga University

Abdulahi Aden Abdi

Jigjiga University

Fuad Ismail Daud ( $\nabla$ f13876893@gmail.com )

Jigjiga University

\section{Research Article}

Keywords: Micro-albuminuria, Type II diabetes, nephropathy, Jigjiga town, Public hospital

Posted Date: October 14th, 2021

DOl: https://doi.org/10.21203/rs.3.rs-936394/v1

License: (c) (1) This work is licensed under a Creative Commons Attribution 4.0 International License.

Read Full License 
Page $2 / 26$ 


\section{Abstract}

\section{Background and Aim}

Under normal circumstances, a urine albumin excretion of $5-10 \mathrm{mg} / \mathrm{L}$ is considered to be normal. Microalbuminuria is, however, defined as a level of albumin in the urine that is between $20 \mathrm{mcg} / \mathrm{min}$, and 200 $\mathrm{mcg} / \mathrm{min}(30-300 \mathrm{mg} / 24 \mathrm{~h})$ with normal urine flow of $1 \mathrm{ml} / \mathrm{min}$.

The aim of this study is to assess the prevalence of micro-albuminuria and associated factors among adult type two diabetes mellitus clients in public hospitals of Jigjiga town, Somali region, Ethiopia, from April 1 to July 15,2020

Methods: Institutional based cross-sectional study design was used from April 1 to July 15, 2020. A pretested structured questionnaire was used to collect a data from 204 Type 2 diabetes mellitus patients visiting at Karamara general and Jigjiga University referral hospitals for follow up. Descriptive statistics was computed. Logistic regression model was used to identify covariates using SPSS version 20 . The direction and strength of statistical association was measured by odds ratio with $95 \% \mathrm{Cl}$ and a P-value < 0.05 was considered as statistically significant.

Results: The prevalence of micro-albuminuria was $48.0 \%$ with $[95 \% \mathrm{Cl}(41.2,54.9)]$ Duration of DM between $11-20$ years [AOR=3.71; $95 \% \mathrm{Cl}(1.45,9.49)]$ Family history of hypertension [AOR=2.24; $95 \% \mathrm{Cl}$ : $(1.02,4.70)]$ Systolic blood pressure [AOR=3.36; $95 \% \mathrm{Cl}:(1.39,8.13)]$, Low density lipoprotein $[\mathrm{AOR}=5.60$; $95 \% \mathrm{Cl}:(2.22,14.11)]$ High density lipoprotein $[\mathrm{AOR}=5.210 ; 95 \% \mathrm{Cl}(2.067,13.131)]$ and Glycated hemoglobin $[A O R=3.246 ; 95 \% \mathrm{Cl}(1.356,7.78)]$ were significantly associated with micro-albuminuria

Conclusion: There is a significant level of micro-albuminuria among type 2 diabetes mellitus patients. Effective secondary prevention program directed on blood glucose and lipid with steps to improve blood pressure are critical in undertaking in the setting and regular screening of micro-albuminuria is needed so that an early preventive and treatment measures against its burden are put in place.

\section{Introduction}

Diabetes mellitus, (DM) a condition that is seen when the person's blood glucose rises because of complete absence of insulin (hormone that regulates blood glucose), or enough of it cannot be produced, or in certain conditions body is not able to use insulin when in fact it is being produced in the body. In type 2 diabetes, blood glucose rises due to the inability of the body's cells to respond fully to insulin, Though majority cases of Type 2 diabetes are commonly seen in older adults, nowadays children and younger adults are involved due to factors related to lifestyle [1].

Whatever its form (type I and II), diabetic mellitus may lead to many clinical complications including kidney failure that can lead to premature death, [2].It is also possible to categorize complications from 
both forms of diabetic mellitus that cause serious morbidity as nephropathy, neuropathy and retinopathy[3].

Under normal circumstances, a urine albumin excretion (UAE) of $5-10 \mathrm{mg} / \mathrm{L}$ is considered to be normal[4]. Microalbuminuria is , However, defined as a level of albumin in the urine that is between $20 \mathrm{mcg} / \mathrm{min}$, and $200 \mathrm{mcg} / \mathrm{min}(30-300 \mathrm{mg} / 24 \mathrm{~h})$ with normal urine flow of $1 \mathrm{ml} / \mathrm{min}$, below and above this range is called normo-albuminuric and macro-albuminuria, respectively $[5,6]$

Nearly half of patients with diabetes develop diabetic nephropathy, the single leading cause of end-stage renal disease (ESRD). Microalbuminuria is a marker for the development of diabetic nephropathy in type II diabetes mellitus. After some period of living with $\mathrm{DM}$, a patient with microalbuminuria may go to another stage called macroalbuminuria ,(albuminuria above $200 \mathrm{mg} / \mathrm{min}$ ) which necessitates the risk of progressing to ESRD[7].

Furthermore, the presence of microalbuminuria determines increased risk for heart disease as well as vascular damage due to arterial defects and endothelial dysfunction[8]. Diabetic nephropathy, initially marked by microalbuminuria may be the result of various underlying risk factors with individual glycemic control and excess weight being the leading ones [9-11].The fact that microalbuminuria can pose a huge threat to life by progressing to more serious stages like proteinuria, it is recommended that an individual with DM early checks for albuminuria in a period that is one year apart[12]

According to international diabetic federation (IDF), globally, from a total of 5 billion, an estimated 463 million adults between the ages of 20-79 years (9.3\%) have diabetes, and a total of 4.2 million deaths due to it. More than three fourth of these people live in countries considered to be low and middle income, with prevalence rate of $(9.5 \%$ and $4 \%)$ respectively. By the year 2030 it is projected worldwide that the number of patients with DM will increase and climb 578.4 million, about (2.26\%) increase in the prevalence of DM to the current rate. More than 310 million (10.8\%) of diabetic patients live in urban settings, whereas almost 153 million (7.2\%) live in rural areas[1]. Over the past three decades, globally the prevalence of DM has been gaining momentum with an estimated $4.7 \%$ in the year 1980 to $8.5 \%$ in 2014[2]

In 2019 China and India (the two most populous countries in the world) are the leading in the number of people living with DM (more than 116 million and 77 million, respectively) [1].

A recent report from over fifty countries shows that $55 \%$ of individuals living with $\mathrm{DM}$, develop an end stage renal disease[2]. In western countries one fourth of patients with T2DM develop diabetic nephropathy with recent study showing that diabetic nephropathy (DN) is the single leading cause of end stage renal disease and replacement[13].

In the United Kingdom Prevalence of microalbuminuria (MA) among T2DM patients was reported to be less than $10 \%$ compared with Hispanic Americans in which the prevalence was 35\% [14].Another report 
also states that the prevalence of microalbuminuria was high among individuals from South Asia (31\%) when compared with white Europeans (20\%)[15].

More than 19 million (3.9\%) people in Africa between the age of 20-79 have DM of which nearly $75 \%$ die due to it. More than $55 \%$ of these people live in four countries with highest population which are South Africa (4.6), Nigeria (2.7), DRC (1.8)and Ethiopia(1.7million people)[1]. The prevalence of DM in Africa has been increasing over the last 3 decades, and even becoming the leading region per population of DM in the years to come. The reasons behind this increase may be due to scarce screening and diagnostics resources which may in turn delay early diagnosis and treatment[16].

Diabetic nephropathy is characterized by an increased albumin in the urine (UAE) without primary kidney problems [17]. Although Diabetic Nephropathy has been generally increasing with an increase in DM[16], its prevalence was reported to be higher in blacks[18, 19]. That much studies are not available showing microalbuminuria prevalence at Africa level, however, some studies confirm variations in the prevalence of microalbuminuria from 9.2\% in Tanzania [20] to $47 \%$ in Uganda[21]. In Ethiopia almost 1.7 million (3.2) individuals have been reported to have DM and it is expected that this number to rise in the years to come[1],An available literature from Gondar town, northern Ethiopia indicates that the prevalence of microalbuminuria in Ethiopia was 37\%[22].

Various risk factors have been related to microalbuminuria. In a study conducted in Albania by Pasko.N. and colleagues stated an increase in the level microalbuminuria as the duration with which the individual lives with DM increases, it also reported that macroalbuminuric clients had an increase in their blood pressure (both systolic and diastolic) compared to those who were normoalbuminuric[23]. A similar study conducted in Southern India showed macroalbuminuric individuals had an increased fasting blood glucose and glycated hemoglobin (HbA1c) when compared with their normoalbuminuric counterparts [24].

Being at older age, obese, overweight, hypertriglyceridemia and hypercholesterolemia were all associated with microalbuminuria[6].Different studies have outlined intervention for microalbuminuria, among those is a study involved in systematic review by Frederik Persson and fellows which reported treating with angiotensin converting enzyme inhibitor (ACEi), has yielded less compared to placebo in preventing the development of microalbuminuria[25]. Similar study but conducted in a large scale-cluster randomization revealed restrictions in the dietary sodium intake to have significantly reduced albuminuria[26].

Several studies which measures the prevalence of microalbuminuria and its associated factors; have been done elsewhere, conversely, only few studies were done in Ethiopia, on the prevalence of microalbuminuria among T2DM, therefore the aim of this study was to determine the prevalence and associated factors of microalbuminuria among T2DMpatients in Jigjiga town public hospitals, Somali Regional state, Eastern Ethiopia, 2020 using a cross sectional study design.

Public and private health care institutions in Somali region, only screen for overt proteinuria (macroalbuminuria) which is considered to be a marker for advanced stages of renal disease or some 
other physiological conditions, like fever and infections particularly urinary tract by using dipsticks(qualitative methods that cannot detect small amount of protein in the urine), However, microalbuminuria needs to be screened so that it can be treated before it becomes macro-albuminuria and diabetic nephropathy.

The first and major importance of this study will therefore be generating valuable evidences regarding the associated factors of microalbuminuria, a clinical marker of renal involvement in T2DM patients in the context of Somali region, eastern Ethiopia. Secondly, the results of the study will be much useful to the actual diabetic clients, health care facilities (Hospitals, health centers etc.), and in setting appropriate preventive and therapeutic measures in addressing diabetic nephropathy and this study may become a baseline data for researchers who are interested in this topic.

\section{Methods And Materials General objective}

To assess the prevalence and associated factors of microalbuminuria among type2 diabetes mellitus patients in Jigjiga town public hospitals, Somali Regional State, Eastern Ethiopia, from April 1 to July 15,2020

\section{Study area and Study period}

\section{Study area}

Somali Regional State is one of 10 regional states of the Federal Democratic Republic of Ethiopia located in the Eastern part of Ethiopian lowlands. The region has 11 zones and more than 90 Woreda administrations. The study was conducted in Jigjiga town, capital of Somali Regional State located 635 $\mathrm{km}$ from Addis Ababa to the East. The town has one referral Hospital, one general hospital, 3 health centers and 20 health posts (government), 27 higher clinics, 10 medium clinics. This study was, however, be specifically conducted in Jigjiga University Sultan Sheik Hasan Referral Hospital (JJUSSHRH) and Karamara General Hospital (KGH) where 500 T2DM clients make regular visits for follow up.

\subsubsection{Study period}

The study was conducted from April 1 to July 15, 2020

\section{Study design}

Institutional based cross-sectional study design was used.

\section{Inclusion and exclusion criteria}




\section{Inclusion criteria}

All T2DM clients willing to provide information and take part in the survey

\section{Exclusion criteria}

Menstruating women, those who have urinary tract infection, Hematuria, critically ill, those who present with acute febrile illnesses (AFI), Pregnancy, Suspected/diagnosed renal or hepatic or any systemic disorders i.e., sickle cell anemia

\section{Sample size determination}

\section{Sample size for the first objective}

The sample size was calculated by using single population proportion formula considering a $95 \%$ confidence interval, $5 \%$ margin of error and prevalence of micro-albuminuria $37 \%$ [22].

\section{The total sample size $=358$}

Since, the source population was 500 , which is below 10,000 , population correction formula was used. The final sample size of this study was $=222$

\section{Sampling technique}

All 222 study units were consecutively selected upon arrival and included in the study

\section{Sampling procedure}

The study participants were allocated for the two hospitals in a manner that was proportional to their number of clients registered and come for follow up. JJUSHRH had a total of 350 T2DM clients while KGH had a total of 150 .

To proportionate the number of study subject for each hospital, the formula $=\mathrm{n}=\frac{\mathrm{n} * \mathrm{nf}}{\mathrm{N}}$ was used. Where $\mathrm{n}=$ number of clients registered for follow up in each hospital, $\mathrm{nf}=$ total sample size and $\mathrm{N}=$ the total number clients registered for follow up in the two hospitals.

The proportional size For JJUSHRH was as follows $\mathrm{n}=\frac{350 * 222}{500}=155$ 
The proportional size For KGH was as follows

$$
\mathrm{n}=\frac{150 * 222}{500}=67
$$

\section{Data collection methods and materials}

A structured questionnaire was used to interview clients in order to collect data on socio -demographic and clinical variables. Anthropometric measurements such as, Weight of the client in kilograms $(\mathrm{kg})$ was measured to the nearest $0.1 \mathrm{~kg}$ using calibrated weighing scale and Height of the client in meters $(\mathrm{m})$ was measured in standing position with shoes removed using stadiometer to the nearest $0.1 \mathrm{~cm}$. Body mass index of the client in $(\mathrm{kg} / \mathrm{m} 2)$ was also measured and then classified based on the WHO reference values as underweight if less than 18.5, Normal if 18.5-24.99, overweight 25-29.99 and obese if greater than $30 \mathrm{~kg} / \mathrm{m} 2[2]$.

Routine physical examination was done on clients by the physicians available at the chronic clinics or outpatient departments (OPDs) as the clients visited the hospitals and those found to have significant complications of systemic disorders like cardiovascular disorders and hepatic enlargement (through palpation) were excluded from the study.

Blood pressure in millimeter mercury $(\mathrm{mmHg})$ in sitting position was measured using Sphygmomanometer and stethoscope from the left arm after the individual rested for about 5 minutes, in order to record the data, an average of two measurements which are 5 minutes apart were done and finally taken as the blood pressure results of the clients. Clients were classified as hypertensive if they had systolic blood pressure of $>140 \mathrm{mmHg}$ and/or diastolic blood pressure of $>90 \mathrm{mmHg}$ or known to be hypertensive on medications (antihypertensive).

Venipuncture (venesection) was performed through aseptic technique and $8 \mathrm{ml}$ of blood was collected in test tube, then the blood was analyzed within the day of collection, for complete blood count (CBC). Serum creatinine, low density lipoprotein (LDL), high density lipoprotein (HDL)and blood urea nitrogen (BUN)was measured using Biosystems A25 chemistry analyzer. Glycosylated hemoglobin (HbA1c) which represents glycemic control for the last three months with the aid of EDTA containing test tubes was also analyzed using Fine care $\mathrm{HbA} 1 \mathrm{c}$ analyzer, and the results of the test were categorized as good control if the $\mathrm{HbA} 1 \mathrm{c}$ value was $<7 \%$ and poor control if it was $>7 \%$.FBS was measured using Prodigy Auto Code which displays the readings quantitatively and the result was categorized as normal if $<80$ $130 \mathrm{mg} / \mathrm{dl}$ (only for known DM patients) and high if $>130 \mathrm{mg} / \mathrm{dl}$. All sample were analyzed with in the day of collection.

A morning spot mid-stream urine specimen of $10 \mathrm{ml}$ was collected using pre-treated containers, $5 \mathrm{ml}$ was taken from the $10 \mathrm{ml}$ using a syringe to another container for urine analysis using dipstick to check the presence of proteins, glucose, red and white blood cells. Presence of the above-mentioned substances in the urine, were dealt with an appropriate treatment through the available physicians. Microalbuminuria was checked using HemoCue ${ }^{\circledR} 201$ albumin analyzer (HemoCue ${ }^{\circledR}$, Ängelholm, Sweden) and its microcuvettes, HemoCue ${ }^{\circledR} 201$ albumin analyzer is a factory calibrated electronic device that employs 
immunoturbidimetry and quantitatively measures a slight amount of albumin in the urine that the dipsticks cannot detect.

Microalbuminuria was measured three times one month apart then microalbuminuria was considered positive if two out of three tests within 3 months read $20-199 \mathrm{mg} / \mathrm{L}[27]$.

Since all patients having the follow ups in these two hospitals were mainly residents of Jigjiga town and its surrounding (rural kebeles), upon meeting with the clients for the first visit, personal address like telephone and possible way of communication like neighborhood and house number were asked so that it becomes easier for the data collectors to reach/visit those who do not (if any) make a visit to the hospitals in the next follow up.

\section{Data collectors}

The data was collected by four diploma laboratory technologists and two BSc nurses (3 for each hospital) who were under the guidance of one BSc nurse holder supervisor for each hospital.

\section{Procedure for data collection}

Before data collection, four days of training were given for both the data collectors and supervisors by a senior laboratory technologist. Before interviewing, the data collectors informed the clients about the aims/purposes, possible risks (from physical discomfort to potential inflammation of the veins) and possible benefits of the study (potential change in the treatment protocol of their chronic disorder), the right and refusal to participate in the study. The collected information was kept confidential. Participants who were willing and sign the voluntary consent form were interviewed. Data was collected through faceto-face interviews using unstructured and pretested questionnaire.

\section{Variables}

\section{Dependent variables}

Microalbuminuria (positive, Negative)

\section{Independent variables}

The independent variables for this study obtained from review of different literatures and then grouped in to three domains, demographic, behavioral and life style, clinical and biochemical

Demographic variables: - Age, Sex, Marital status and educational status

Behavioral and life style variables: Smoking and physical activity

Clinical variables: -Duration of DM, Systolic blood pressure, Diastolic blood pressure, Body mass index (BMI) 
Biochemical variables: -Glycosylated hemoglobin, Fasting plasma glucose, BUN, Serum creatinine, Low density lipoprotein, High density lipoprotein

\section{Data quality control}

Four days of training were provided for the data collectors and supervisors. Pre testing of questionnaire was done at two selected private clinics in the same town and calibration of instruments was made to ensure the quality of data, to assess the reliability, clarity, sequence, consistency, and the total time that it will take to finish the questionnaire before the actual data collection begins. Then after, the necessary feedbacks were incorporated in the final tool to improve its quality. Principal investigator and supervisors made spot-checking and reviewing all the completed questionnaires and specimens to ensure completeness and consistency of the information collected. Data entry was done by the principal investigator to keep accuracy of the data. The specimen was labeled with codes that match with the codes of the questionnaires to prevent mismatch of specimen and respective questionnaires.

\section{Operational definitions}

Microalbuminuria: in this study, a urinary albumin excretion (UAE) that is between $20-199 \mathrm{mg} / \mathrm{Laws}$ considered microalbuminuria as defined by Lloyd MM[28]

Chronic clinics: clinics in the hospitals that serve clients with long term systemic disorders like diabetes mellitus and hypertension

FBS: Fasting Blood Glucose for diabetic patients was blood glucose taken after 8 hours of not eating and drinking other than water and categorized as good FBS (only for diabetic) if $\langle 80-130 \mathrm{mg} / \mathrm{dl}$ and high if $\rangle$ $130 \mathrm{mg} / \mathrm{dl}$ as recommended by WHO/IDF 2006 on hyperglycemia: report[29].

BMI: in this study, body Mass Index computed from weight in $\mathrm{kg}$ divided by height in meter squared and was considered as underweight if less than 18.5, Normal if 18.5-24.99, overweight 25-29.99 and obese if greater than $30 \mathrm{~kg} / \mathrm{m} 2$ according to 2016 WHO global report on diabetes [2].

HTN: in this study, a systolic blood pressure $>140 \mathrm{mmHg}$ and or diastolic blood pressure $>90 \mathrm{mmHg}$ was considered as hypertension as defined by guideline for the Prevention, Detection, Evaluation, and Management of High Blood Pressure in Adults[30].

HbA1c: a glycosylated hemoglobin which is $>7 \%$ was considered as poor control and $<7 \%$ as good control in this study according to Sherwani SI[31].

LDL: Low density lipoprotein known as also bad cholesterol was considered as Low if the value are less than $100 \mathrm{mg} / \mathrm{dl}$, Normal if the values fall between $100-130 \mathrm{mg} / \mathrm{dl}$ and High if the value exceeds $130 \mathrm{mg} / \mathrm{dl}$ for Diabetics patients as defined by Suddarth B.[32]. 
HDL: High density lipoprotein was considered as Low if the value was less than $35 \mathrm{mg} / \mathrm{dl}$, Normal if the value falls between $(35-65 \mathrm{mg} / \mathrm{dl})$ for males and $35-85 \mathrm{mg} / \mathrm{dl}$ for females, and high if the value was higher than $65 \mathrm{mg} / \mathrm{dl}$ and $85 \mathrm{mg} / \mathrm{dl}$ for males and females respectively as defined by Suddarth B.[32].

Serum creatinine: was defined as Normal if values fall between $0.7-1.5 \mathrm{mg} / \mathrm{dl}$ and High if greater than $1.5 \mathrm{mg} / \mathrm{dl}$ as defined by Suddarth B.[32].

\section{Data processing and analysis}

The data was entered into statistical software Epi data version 3,1, double data entry was made and then, exported to SPSS version 20after exporting the prepared data. Descriptive statistics such as frequency distribution was computed to describe variables of the study. The data was described and presented using narrative text, tables, and chart.

Logistic regression model was used to analyze the outcome variable. It was performed in two stages; in first stage a bivariate analysis was conducted to identify a candidate's covariates for multivariate analysis at p-value less than 0.25 . In the second stage, multivariate analysis was done to see the association between the outcome variable and independent variables which were significant at bivariate stage. The direction and strength of statistical association was measured by odds ratio with $95 \% \mathrm{Cl}$. In this study P-value $<0.05$ was considered as statistically significant.

The model adequacy and fitness were checked using Hosmer-Lemeshow goodness of fit test and all assumptions of regression analysis (model adequacy and multi collinearity of the independent variables) was also checked. Multi-collinearity was checked using variance inflated factor (VIF)/ tolerance and no multi-collinearity was found between variables.

\section{Ethical considerations}

All methods were done in accordance with the declaration of Helsinki. Ethical clearance was obtained from the Institutional Health Research Ethics Review Committee (JJU-IHRERC College of Medicine and health sciences,) of Jigjiga University. For Karamara General Hospital, a formal letter of permission and support was written to regional health bureau which is responsible for regional controlled hospitals and for Sheik Hasan Referral Hospital, Jigjiga University has written a letter to it as it's under the control of the university. All the study participants were informed about the purpose of the study, their right to refuse was stressed and written and signed voluntary consent was obtained from all study participants prior to data collection. The respondents were assured that the information as well as specimens obtained from them will not be used for any other purpose and treated with complete confidentiality. Clients who test positive for microalbuminuria during data collection were linked back to their OPD for an appropriate treatment. 


\section{Plan for Information dissemination}

The findings of this study will be submitted and presented to the School of Graduate Studies, College of Medicine and Health Sciences, of Jigjiga University. The findings of this study will also be disseminated to JJUSHRH and KGH. Furthermore, publication of this thesis will be tried as one major dissemination strategy.

\section{Results}

\section{Socio- Demographic Characteristics of the Study Participants}

Out of the 222 study participants primarily sampled for the study, 204 have participated making the response rate $91.9 \%$. The mean age of the study participants was 55.90 with SD of \pm 13.33 , the minimum and maximum age of the study participants was 24 and 82 years respectively (Table 1 ) 
Table 1

Distribution of Socio-Demographic Characteristics of the Study

Participants

\begin{tabular}{|c|c|c|c|}
\hline Variable & Category & $\begin{array}{l}\text { Frequency } \\
\text { (No) }\end{array}$ & $\begin{array}{l}\text { Frequency } \\
\text { (\%) }\end{array}$ \\
\hline \multirow[t]{4}{*}{ Age } & $21-30$ & 8 & 3.9 \\
\hline & $31-40$ & 45 & 22.1 \\
\hline & $41-50$ & 71 & 34.8 \\
\hline & $>50$ & 80 & 39.2 \\
\hline \multirow[t]{5}{*}{ Ethnicity } & Somali & 138 & 67.6 \\
\hline & Oromo & 26 & 12.7 \\
\hline & Amhara & 17 & 8.3 \\
\hline & Tigray & 12 & 5.9 \\
\hline & Gurage & 11 & 5.4 \\
\hline \multirow[t]{2}{*}{ Sex } & Male & 97 & 47.5 \\
\hline & Female & 107 & 52.5 \\
\hline \multirow[t]{4}{*}{ Marital Status } & Divorced & 10 & 4.9 \\
\hline & Widowed & 39 & 19.1 \\
\hline & Married & 146 & 71.6 \\
\hline & Never married & 9 & 4.4 \\
\hline \multirow[t]{5}{*}{ Educational Status } & Can't read and write & 39 & 19.1 \\
\hline & Can read and write & 47 & 23.0 \\
\hline & Primary school & 40 & 19.6 \\
\hline & Secondary school & 54 & 26.5 \\
\hline & Higher education & 24 & 11.8 \\
\hline
\end{tabular}

\section{Clinical, Behavioral and life-style factors}

From the total of 204 participants, 104(51.0\%) smoked. More than half 109(53.4\%) of the participants were engaged in physical activity and nearly half $97(47.5 \%)$ of them have been living with diabetes period less than five years. $136(66.7 \%)$ of the study participants had family history of hypertension, almost three fourth $152(74.5 \%)$ of the study participants had a normal systolic blood pressure (SBP) on examination, 
while on the other hand $127(62.3 \%)$ of them had a normal diastolic blood pressure (DBP). Regarding the BMl of the study participants, $109(53.4 \%)$ were categorized as being obese. (Table 2 )

Table 2

Descriptive Analyses of factors (Clinical, Behavioral and lifestyle factors) associated with Micro-albuminuria among type 2

DM patients in Public Hospitals of Jigjiga town 2020.

\begin{tabular}{|c|c|c|c|}
\hline \multirow[t]{2}{*}{ Variable } & \multirow[t]{2}{*}{ Category } & Frequency & Frequency \\
\hline & & No & $\%$ \\
\hline \multirow[t]{2}{*}{ Smoking } & Yes & 104 & 51.0 \\
\hline & No & 100 & 49.0 \\
\hline \multirow[t]{2}{*}{ Physical Activity } & Yes & 109 & 53.4 \\
\hline & No & 95 & 46.6 \\
\hline \multirow[t]{3}{*}{ Duration of DM } & $<5$ years & 97 & 47.5 \\
\hline & $5-10$ years & 50 & 24.5 \\
\hline & $11-20$ years & 57 & 27.9 \\
\hline \multirow{2}{*}{$\begin{array}{l}\text { familyHistory of } \\
\text { Hypertension }\end{array}$} & Yes & 136 & 66.7 \\
\hline & No & 68 & 33.3 \\
\hline \multirow[t]{2}{*}{ SBP } & Normal & 152 & 74.5 \\
\hline & High & 52 & 25.5 \\
\hline \multirow[t]{2}{*}{ DBP } & Normal & 127 & 62.3 \\
\hline & High & 77 & 37.7 \\
\hline \multirow[t]{3}{*}{ BMI } & Normal & 55 & 27 \\
\hline & Overweight & 40 & 19.6 \\
\hline & Obese & 109 & 53.4 \\
\hline
\end{tabular}

\section{Biochemical factors}

Majority of the study participants $106(52.0 \%)$ were normo-albuminuria (negative), compared with 98(48.0\%) who were micro-albuminuria (positive). About 77(37.7\%.) had High low-density lipoprotein (LDL) and more than one fourth, 73(35.8\%) had a Low high-density lipoprotein (HDL). Regarding the BUN $124(60.8 \%)$ had a normal blood urea nitrogen level, study participants whose creatinine level was high 
were $181(88.7 \%)$ and about $108(52.9 \%)$ of the participants had a normal fasting blood sugar. Concerning glycated hemoglobin (HbA1c) 118(57.8\%) were having a poor control over their diabetes (Table 3).

Table 3

Descriptive Analyses of factors (Biochemical factors) associated with microalbuminuria among type 2 DM patients in Public Hospitals of Jigjiga town 2020.

\begin{tabular}{|llll|}
\hline Variable & Category & Frequency & Frequency \\
& & No & $\%$ \\
\hline LDL & Low & 75 & 36.8 \\
\cline { 2 - 4 } & Normal & 52 & 25.5 \\
\cline { 2 - 4 } & High & 77 & 37.7 \\
\hline HDL & Low & 73 & 35.8 \\
\cline { 2 - 4 } & Normal & 62 & 30.4 \\
\cline { 2 - 4 } & High & 69 & 33.8 \\
\hline BUN & Normal & 124 & 60.8 \\
\cline { 2 - 4 } & High & 80 & 39.2 \\
\hline Creatinine & Normal & 23 & 11.3 \\
\cline { 2 - 4 } & High & 181 & 88.7 \\
\hline FBS & Normal & 108 & 52.9 \\
\cline { 2 - 4 } & High & 96 & 47.1 \\
\hline Glycated hemoglobin $(\mathrm{HbA1c})$ & Good control & 86 & 42.2 \\
\cline { 2 - 4 } & poor control & 118 & 57.8 \\
\hline & & & \\
\hline
\end{tabular}

\section{Prevalence of Micro-albuminuria}

The prevalence of microalbuminuria in this study was found to be $48.0 \%$ with $[95 \% \mathrm{Cl}(41.2,54.9)]$ (Fig. 1)

\section{Factors associated with micro-albuminuria}

\section{Multivariate Analyses of Factors Associated with microalbuminuria}

Those independent variables which had association with the outcome during bivariate analysis with Pvalue $<0.25$ were included in to the final model of multivariate analysis in order to control all possible confounders. 
In the multivariable analyses, duration of DM between 11-20years significantly associated with microalbuminuria with AOR of 4 times [AOR $=3.708 ; 95 \% \mathrm{Cl}:(1.449,9.490)]$ compared to $<5$ and $5-10$ years. Those with Family history of hypertension were 2 times [AOR=2.237; $95 \% \mathrm{Cl}:(1.023,4.894)]$ more likely to microalbuminuria compared to those who had not Family history of hypertension. Patients whose Systolic blood pressure was high were3folds $[\mathrm{AOR}=3.356 ; 95 \% \mathrm{Cl}:(1.385,8.131)]$ more likely to have microalbuminuria compared to those with normal systolic blood pressure. And patients with high, Lowdensity lipoproteins (LDL) were nearly 6 times [AOR $=5.599 ; 95 \% \mathrm{Cl}(2.222,14.108)]$ more likely to have microalbuminuria compared to their counter parts while on the other hand, patients with low High-density lipoproteins $(\mathrm{HDL})$ were 5 folds $[\mathrm{AOR}=5.210 ; 95 \% \mathrm{Cl}(2.067,13.131)]$ more likely to have microalbuminuria compared to their counterpart. Patients with poor control of their glycemic were 3times $[A O R=3.246 ; 95 \% \mathrm{Cl}(1.356,7.771)]$ more likely to have microalbuminuria, compared to those with good control over their glycemic (Table 4). 
Table 4

Multivariable Logistic Regression Analyses for Factors Associated with micro-albuminuria among type 2 DM patients in Jigjiga town Public Hospitals, Somali Region, Eastern Ethiopia, 2020.

\begin{tabular}{|c|c|c|c|c|c|}
\hline \multirow[t]{3}{*}{ Variable } & \multirow[t]{3}{*}{ Category } & \multicolumn{2}{|c|}{ Micro-albuminuria } & \multirow[t]{3}{*}{ AOR $(95 \% \mathrm{Cl})$} & \multirow{3}{*}{$\begin{array}{l}\mathrm{P}- \\
\text { value }\end{array}$} \\
\hline & & Positive & Negative & & \\
\hline & & $\mathrm{N}(\%)$ & $\mathbf{N}(\%)$ & & \\
\hline \multirow[t]{2}{*}{ Sex } & Male & $56(57.7)$ & $41(42.3)$ & $\begin{array}{l}\text { 1.651(0.743, } \\
3.668)\end{array}$ & 0.218 \\
\hline & Female & 42(39.3) & $65(60.7)$ & 1.00 & \\
\hline \multirow[t]{2}{*}{ Smoking } & Yes & $42(40.4)$ & $62(59.6)$ & $\begin{array}{l}0.822(0.378 \\
1.788)\end{array}$ & 0.620 \\
\hline & No & $56(56.0)$ & $44(44.0)$ & 1.00 & \\
\hline \multirow[t]{3}{*}{ Duration of DM } & 1-5years & $39(40.2)$ & $58(59.8)$ & 1.00 & \\
\hline & $5-10$ years & $17(34.0)$ & $33(66.0)$ & $\begin{array}{l}1.058(0.404 \\
2.772)\end{array}$ & 0.908 \\
\hline & $11-20$ years & 42(73.7) & $15(26.3)$ & $\begin{array}{l}3.708(1.449 \\
9.490)\end{array}$ & 0.006 \\
\hline \multirow[t]{2}{*}{ family $\mathrm{Hx}$ of Hypertension } & Yes & $80(58.8)$ & $56(41.2)$ & $\begin{array}{l}2.237(1.023 \\
4.894)\end{array}$ & 0.044 \\
\hline & No & $18(26.5)$ & $50(73.5)$ & 1.00 & \\
\hline \multirow[t]{2}{*}{ SBP } & Normal & $62(40.8)$ & $90(59.2)$ & 1.00 & \\
\hline & High & $36(69.2)$ & $16(30.8)$ & $\begin{array}{l}3.356(1.385 \\
8.131)\end{array}$ & 0.007 \\
\hline \multirow[t]{2}{*}{ DBP } & Normal & $57(44.9)$ & $70(55.1)$ & 1.00 & \\
\hline & High & $41(53.2)$ & $36(46.8)$ & $\begin{array}{l}0.642(0.290 \\
1.424)\end{array}$ & 0.276 \\
\hline \multirow[t]{3}{*}{ BMI } & Normal & $22(40.0)$ & $33(60.0)$ & 1.00 & \\
\hline & Overweight & $26(65.0)$ & $14(35.0)$ & $\begin{array}{l}1.691(0.571 \\
5.004)\end{array}$ & 0.343 \\
\hline & Obese & $50(53.2)$ & $59(53.2)$ & $\begin{array}{l}0.616(0.256 \\
1.483)\end{array}$ & 0.280 \\
\hline \multirow[t]{3}{*}{ LDL } & Low & $27(36.0)$ & $48(64.0)$ & 1.00 & \\
\hline & Normal & $20(38.5)$ & $32(61.5)$ & $\begin{array}{l}1.790(0.696 \\
4.606)\end{array}$ & 0.227 \\
\hline & High & $51(66.2)$ & $26(33.8)$ & $\begin{array}{l}5.599(2.222 \\
14.108)\end{array}$ & 0.000 \\
\hline
\end{tabular}




\begin{tabular}{|c|c|c|c|c|c|}
\hline \multirow[t]{3}{*}{ Variable } & \multirow[t]{3}{*}{ Category } & \multicolumn{2}{|c|}{ Micro-albuminuria } & \multirow[t]{3}{*}{ AOR $(95 \% \mathrm{Cl})$} & \multirow{3}{*}{$\begin{array}{l}\mathrm{P} \text { - } \\
\text { value }\end{array}$} \\
\hline & & Positive & Negative & & \\
\hline & & $\mathbf{N}(\%)$ & $\mathbf{N}(\%)$ & & \\
\hline \multirow[t]{3}{*}{ HDL } & Low & $50(68.5)$ & 23(31.5) & $\begin{array}{l}5.210(2.067 \\
13.131)\end{array}$ & 0.000 \\
\hline & Normal & $24(38.7)$ & $38(61.3)$ & $\begin{array}{l}1.223(0.487 \\
3.070)\end{array}$ & 0.668 \\
\hline & High & $24(34.8)$ & $45(65.2)$ & 1.00 & \\
\hline \multirow[t]{2}{*}{ BUN } & Normal & $32(40.0)$ & $48(60.0)$ & 1.00 & \\
\hline & High & $66(53.2)$ & $58(46.8)$ & $\begin{array}{l}0.734(0.324 \\
1.661)\end{array}$ & 0.458 \\
\hline \multirow[t]{2}{*}{ FBS } & Normal & $46(42.6)$ & $62(57.4)$ & 1.00 & \\
\hline & High & $52(54.2)$ & $44(45.8)$ & $\begin{array}{l}1.856(0.886 \\
3.886)\end{array}$ & 0.101 \\
\hline \multirow[t]{2}{*}{$\begin{array}{l}\text { Glycated hemoglobin } \\
\text { (HbA1c) }\end{array}$} & $\begin{array}{l}\text { Good } \\
\text { control }\end{array}$ & $36(41.9)$ & $50(58.1)$ & 1.00 & \\
\hline & poor control & $62(52.5)$ & $56(47.5)$ & $\begin{array}{l}3.246(1.356 \\
7.771)\end{array}$ & 0.008 \\
\hline
\end{tabular}

\section{Discussion}

In this study the prevalence of microalbuminuria was found to be $48.0 \%$ This study also reports that Duration of DM, Family history of hypertension, systolic blood pressure, Low density lipoprotein, High density lipoprotein and Glycated/glycosylated were significantly associated with Microalbuminuria

The prevalence of this study is much higher than the prevalence reported in the study conducted in Singapore which was $14.2 \%$ [33], the prevalence of $17.2 \%$ in northern Iran[34] and that of $20.3 \%$ reported in Kathmandu, Nepal[35].These variations may be attributed mainly to differences between study areas, period, sample size and the tools and devices used to measure microalbuminuria which was Dako and Albumin-Creatinine ratio (ACR) In this study, however, we used HemoCue albumin analyzer.

Microalbuminuria reported in the cross-sectional studies conducted in Karachi, Pakistan with a prevalence rate of 31.56\%[36],35.1\% reported in Ogun State in Nigeria[37], and 37\% reported in Gondar, Ethiopia[22],all of which may be due to differences in study period, sample size, measuring tools, methods used, and also definitions of microalbuminuria where microalbuminuria was defined by these studies as albumin to creatinine ratio ranging from 30 to $300 \mathrm{mg} / \mathrm{g}$ in a 24-hour urine collection, (ours defined as ranging $20-199 \mathrm{mg} / \mathrm{l}$ in a morning spot urine collection). were also markedly lower than the prevalence rate of this study. 
This study has found a prevalence that is comparable with other cross-sectional studies conducted in India, Turkey, and Botswana which have reported prevalence rate of $41.5 \%, 43.2 \%$ and $44.6 \%$, respectively[18, 38, 39]. It is also consistent with the prevalence of the institutional based cross-sectional study that was conducted in Mulago National referral hospital, Uganda which reported a prevalence of $45.7 \%[21]$

This finding is however much smaller than the prevalence of another similar study conducted at Warri, Nigeria which revealed a prevalence of $58 \%[40]$. Possible difference may be due to the inclusion of higher age groups in the study(45-80years) which seem to focus on older ages and in turn may increase the prevalence of the microalbuminuria, in this study we used age between 18-82years, finally, of course the use of MICRAL test which may also increase the prevalence rate and other possible factors including study period were detected as vital differences.

Micro-albuminuria was nearly 4 times more likely to affect those patients with longer duration of DM. This is in line with various similar studies conducted in Malaysia, Taiwan, Northern Iran, Palestine and Botswana $[6,10,18,34,41]$.This study found that duration of DM between 11-20 years associated with microalbuminuria. This is also supported by the study conducted at Ekiti, Nigeria which revealed a significant association between microalbuminuria and duration of DM greater than 10 years. Possible reason for this association may include, the fact that people living with diabetes for a longer period of time encounter renal involvement due to high persistent sugar concentration in the blood vessels over time and due to the degenerative nature of aging affecting kidneys and blood vessels leading up to the kidneys.

Family history of hypertension was significantly associated with microalbuminuria, this study revealed that microalbuminuria was2times more likely to affect those patients with family history of hypertension. This is supported by the study conducted in Egypt, which revealed a significant association between microalbuminuria and family history of hypertension[42]. This may be attributed to genetical and hereditability means, or on the other hand, family history of hypertension may cause renal damage to the family member (parents) and that may affect the offspring's kidneys

Systolic blood pressure (SBP) was significantly associated with microalbuminuria, in this study, patients with high systolic blood pressure were reported to be 3 times more vulnerable to encountering microalbuminuria. This is in line with the study conducted in Tirana, Albania which reported a significant association between SBP and microalbuminuria[23]. This is also supported by the study conducted in India and Taiwan which both found a significant association between SBP and microalbuminuria [41, 43].

This association may due to fact that an increased blood pressure puts the kidney in a strangulated manner due to Vaso-constriction which makes difficult for the kidneys to find oxygen and nutrient (through blood) which is vital for kidneys' normal functioning including prevention of protein loss through urine. 
Another factor that was found to be significantly associated with microalbuminuria was Low density lipoprotein (LDL), in these study patients with higher LDL were almost 6times more likely to have microalbuminuria. The same is true for the study conducted by Vaidya and colleagues which found significant correlation between LDL and microalbuminuria[43]. This is also supported by the studies conducted in Kerala, Nigeria and Cameroon which all stated the significant association between LDL and micro-albuminuria $[40,44,45]$.

This association may be attributed to the fact that an increased LDL may finally bring about atherosclerosis or fatty deposition of the arterial walls which makes the blood vessels narrower in diameter and that could interrupt blood supply to the kidneys, impairing the kidney's functions and eventually kidneys 'start releasing proteins (Albumin).

This study found that Lower High-density lipoproteins (HDL)was associated with microalbuminuria. This is in line with a previous study conducted in Wari, Nigeria which also reported a significant association between HDL and microalbuminuria[40]. This association may be justified as the HDL also known as good cholesterol helps us remove excess cholesterol (bad cholesterol) from our cells, tissues and sometimes plaques in the blood vessels, and then returns to the liver for subsequent removal, when it becomes lower, microalbuminuria may be seen.

Glycosylated/glycated hemoglobin (HbA1c) was found in this study to have also significantly associated with microalbuminuria, according to this study, patients with poor glycemic control were 3times more likely to have microalbuminuria. This is consistent with various similar studies including ones conducted in the cities of Islamabad and Peshawar in Pakistan, Albania, Taiwan and some from sub-Saharan Africa $[11,23,41,44-48]$.

Possible justification to this association may be the fact that continuous high sugar levels can damage the small blood vessels across the body and in particular the kidneys, poorly controlled glycemic can also cause damage to the tiny filters of the kidney called glomeruli which filter the blood. Due to the presence of special function called reabsorption, the kidneys have the ability to release waste products while retaining the important substances like macronutrients, of which albumin, a plasma protein is a member when however, blood glucose is poorly controlled the kidneys are damaged and as a result of that kidneys begin leaking proteins (Albumin) through the urine.

\section{Limitations of these study}

Due to financial resource constraints in this study, large enough sample size could have not been determined and that may affect the overall prevalence of this study and may widen the confidence intervals as well.

\section{Conclusions}


There exists a significant level of microalbuminuria among type 2 diabetes mellitus patients with relatively longer duration of diabetes, Family history of hypertension, higher-Low density lipoprotein and lower-High density lipoprotein. Poorly controlled systolic blood pressure and glycemic were identified as two important major modifiable risk factors for microalbuminuria.

\section{Abbreviations And Acronym}

BMI Body Mass Index

BUN Blood Urea Nitrogen

DBP Diastolic Blood Pressure

DM Diabetes Mellitus

ESRD End Stage Renal Disease

FPG/FBS Fasting Plasma/Blood Glucose/Sugar

HbA1c Glycosylated Hemoglobin

HDL High Density Lipoprotein

IDF International Diabetics Federation

JJUSSHRH Jigjiga University Sultan Sheik Hasan Referral Hospital

KGH Karamara General Hospital

LDL Low Density Lipoprotein

MA/MAU Microalbuminuria

SDP Systolic Blood Pressure

SPSS Statistical Package for Social Science

SRHB Somali Region Health Bureau

T2DM Type Two Diabetes Mellitus

WHO World Health Organization

\section{Declarations}


Ethical considerations: All methods were done in accordance with the declaration of Helsinki. Ethical clearance was obtained from the Institutional Health Research Ethics Review Committee (JJU-IHRERC College of Medicine and health sciences,) of Jigjiga University. All the study participants were informed about the purpose of the study, their right to refuse was stressed and written and signed voluntary consent was obtained from all study participants prior to data collection. The respondents were assured that the information as well as specimens obtained from them will not be used for any other purpose and treated with complete confidentiality

Consent for publication: Not applicable

Availability of data and materials: datasets used and/or analyzed during the current study are available from the corresponding author on reasonable request

Competing interests: There is no conflict of interest for this study

Funding: This study did not receive any external funding.

Authors' contributions: All authors contributed equally in different stages of this study

\section{Acknowledgement}

We would like to extend our heartfelt gratitude to Karamara General hospital and Jigjiga University Sheik Hassan Yabare Referral hospital for providing the permission to carry out this study in their facilities, we would also like to thanks our respective data collector for their sincere cooperation and hard work.

\section{References}

1. FEDERATION ID: IDF DIABETES ATLAS, 9 edn; 2019.

2. WHO: GLOBAL REPORT ON DIABETES. In. Edited by Burton A. Geneva, Switzerland; 2016: 88.

3. Nathan DM: Long-Term Complications of Diabetes Mellitus. New England Journal of Medicine 1993, 328(23):1676-1685.

4. Toto RD: Microalbuminuria: definition, detection, and clinical significance. Journal of clinical hypertension (Greenwich, Conn) 2004, 6(11 Suppl 3):2-7.

5. Mogensen CE: Microalbuminuria in prediction and prevention of diabetic nephropathy in insulindependent diabetes mellitus patients. Journal of Diabetes and its Complications 1995, 9(4):337349.

6. Shahwan MJ, Gacem SA, Zaidi SK: Prevalence of Diabetic Nephropathy and associated risk factors among type 2 diabetes mellitus patients in Ramallah, Palestine. Diabetes \& Metabolic Syndrome: Clinical Research \& Reviews 2019, 13(2):1491-1496.

7. Standards of Medical Care for Patients With Diabetes Mellitus. Diabetes Care 2003, 26(suppl 1):s33s50. 
8. Rahamtalla F, Elagib AA, Mahdi A, Ahmed SM: Prevalence of microalbuminuria among sudanese type 2 diabetic patients at elmusbah center at ombadda-omdurman. IOSR J Pharm 2012, 2(5):5155.

9. Iranparvar Alamdari M, Aminisani N, Bashardoost B, Shamshirgaran S, Khodamoradzadeh M, Shokrabadi M, Olomi B: Prevalence and risk factors of microalbuminuria in type 2 diabetic patients in a diabetic clinic of Ardabil-Iran. Int J Endocrinol Metab 2006, 4(1):8-12.

10. Abougalambou SS, Abougalambou AS: Prevalence and risk factors of microalbuminuria in type 2 diabetes mellitus outpatients at University Sains Malaysia Hospital. Diabetes \& metabolic syndrome 2013, 7(2):64-67.

11. Mohammad $\mathrm{P}$, Khan EH: Unnoticed Microalbuminuria is Substantially Prevalent in Patients of Type-2 Diabetes Mellitus in Peshawar. Journal of Saidu Medical College 2019, 9(1).

12. Sja'bani M, Asdie AH, Widayati K, Subroto Y, Kariadi S, Arifin A, Adhiarta I, Permana H, Askandar T: Microalbuminuria prevalence study in hypertensive patients with type 2 diabetes in Indonesia. Acta Med Indones 2005, 37(4):199-204.

13. Oltean S, Coward R, Collino M, Baelde H: Diabetic nephropathy: novel molecular mechanisms and therapeutic avenues. BioMed research international 2017, 2017.

14. Kanakamani J, Ammini A, Gupta N, Dwivedi S: Prevalence of microalbuminuria among patients with type 2 diabetes mellitus-a hospital-based study from north India. Diabetes technology \& therapeutics 2010, 12(2):161-166.

15. Dixon AN, Raymond NT, Mughal S, Rahim A, O'Hare JP, Kumar S, Barnett AH: Prevalence of microalbuminuria and hypertension in South Asians and white Europeans with type 2 diabetes: a report from the United Kingdom Asian Diabetes Study (UKADS). Diabetes and Vascular Disease Research 2006, 3(1):22-25.

16. Noubiap JJN, Naidoo J, Kengne AP: Diabetic nephropathy in Africa: A systematic review. World journal of diabetes 2015, 6(5):759.

17. Gross JL, De Azevedo MJ, Silveiro SP, Canani LH, Caramori ML, Zelmanovitz T: Diabetic nephropathy: diagnosis, prevention, and treatment. Diabetes care 2005, 28(1):164-176.

18. Molefe-Baikai OJ, Molefi M, Cainelli F, Rwegerera GM: The prevalence of microalbuminuria and associated factors among patients with type 2 diabetes mellitus in Botswana. Nigerian journal of clinical practice 2018, 21(11):1430-1437.

19. Ayodele OE, Alebiosu CO, Salako BL: Diabetic nephropathy-a review of the natural history, burden, risk factors and treatment. Journal of the National Medical association 2004, 96(11):1445.

20. Lutale JJK, Thordarson H, Abbas ZG, Vetvik K: Microalbuminuria among type 1 and type 2 diabetic patients of African origin in Dar Es Salaam, Tanzania. BMC nephrology 2007, 8(1):2.

21. Martin M, Edrisa M, SSinabulya I, Samuel K, Frank M, Kiiza MC: Microalbuminuria among Newly Diagnosed Diabetic Patients at Mulago National Referral Hospital in Uganda: A Cross Sectional Study. Journal of obesity and weight-loss medication 2018, 4(1). 
22. Rahlenbeck SI, Gebre-Yohannes A: Prevalence and epidemiology of micro-and macroalbuminuria in Ethiopian diabetic patients. Journal of Diabetes and its Complications 1997, 11(6):343-349.

23. Pasko N, Toti F, Strakosha A, Thengjilli E, Shehu A, Dedej T, Ylli A, Thereska N: Prevalence of microalbuminuria and risk factor analysis in type 2 diabetes patients in Albania: the need for accurate and early diagnosis of diabetic nephropathy. Hippokratia 2013, 17(4):337-341.

24. Varghese A, Deepa R, Rema M, Mohan V: Prevalence of microalbuminuria in type 2 diabetes mellitus at a diabetes centre in southern India. Postgraduate medical journal 2001, 77(908):399-402.

25. Persson $\mathrm{F}$, Lindhardt $\mathrm{M}$, Rossing $\mathrm{P}, \mathrm{Parving} \mathrm{H}-\mathrm{H}$ : Prevention of microalbuminuria using early intervention with renin-angiotensin system inhibitors in patients with type 2 diabetes: A systematic review. Journal of the Renin-Angiotensin-Aldosterone System 2016, 17(3):1470320316652047.

26. Jardine MJ, Li N, Ninomiya T, Feng X, Zhang J, Shi J, Zhang Y, Zhang R, Zhang J, Hao J: Dietary sodium reduction reduces albuminuria: a cluster randomized trial. Journal of Renal Nutrition 2019, 29(4):276-284.

27. Foundation NK: Clinical Practice Guidelines and Clinical Practice Recommendations for Diabetes and Chronic Kidney Disease. In., vol. Am J Kidney Dis 49:S1-S180. 30 East 33rd Street, New York, NY 10016, 800.622.9010: National Kidney Foundation; 2007.

28. Lloyd MM, Kuyl J, Van Jaarsveld H: Evaluation of point-of-care tests for detecting microalbuminuria in diabetic patients. South African Family Practice 2011, 53(3):281-286.

29. Organization WH: Definition and diagnosis of diabetes mellitus and intermediate hyperglycaemia: report of a WHO/IDF consultation. 2006.

30. Whelton PK, Carey RM, Aronow W, Casey Jr D, Collins K, Dennison Himmelfarb C, DePalma S, Gidding $\mathrm{S}$, Jamerson K, Jones D: Guideline for the prevention, detection, evaluation, and management of high blood pressure in adults: a report of the American College of Cardiology/American Heart Association Task Force on Clinical Practice Guidelines. Journal of the American College of Cardiology 2017, 71(6):1269-1324.

31. Sherwani SI, Khan HA, Ekhzaimy A, Masood A, Sakharkar MK: Significance of HbA1c test in diagnosis and prognosis of diabetic patients. Biomarker insights 2016, 11:BMI. S38440.

32. Suddarth B: Medical-Surgical Nursing, 10th edn.

33. Lee ES, Tang WE: The prevalence of albuminuria among diabetic patients in a primary care setting in Singapore. Singapore medical journal 2015, 56(12):681-686.

34. Ansar MM, ShahrokhiRad R, Lebady MK: Risk factors of microalbuminuria and macroalbuminuria in type 2 diabetic patients in north of Iran-Rasht. Nephro-Urology Monthly 2017, 9(1).

35. Thakur SK, Dhakal SP, Parajuli S, Sah AK, Nepal SP, Paudel BD: Microalbuminuria and Its Risk Factors in Type 2 Diabetic Patients. Journal of Nepal Health Research Council 2019, 17(01):61-65.

36. Ahmad T, Ulhaq I, Mawani M, Islam N: Microalbuminuria in Type-2 Diabetes Mellitus; the tip of iceberg of diabetic complications. Pakistan journal of medical sciences 2017, 33(3):519. 
37. Amballi AA, Odusan O, Ogundahunsi OA, Jaiyesimi AA, Oritogun SK, Olooto WE: Prevalence of microalbuminuria among adults with Type 2 Diabetes mellitus at OOUTH, Sagamu. Annals of Health Research 2018, 4(1):15-21.

38. Ambayiram AV, Kalyani P, Felix A, Govindarajan P: Prevalence of microalbuminuria among type II diabetes mellitus patients in urban Chidambaram. Saudi J Med 2016, 1(3):57-62.

39. Fici F, Bakir EA, Beyaz S, Makel W, Robles NR: PAIT-survey-Prevalence of albuminuria in patients with diabetes and hypertension in Turkey. Primary care diabetes 2018, 12(6):558-564.

40. Ufuoma C, Ngozi JC, Kester AD, Godwin YD: Prevalence and risk factors of microalbuminuria among type 2 diabetes mellitus: a hospital-based study from, Warri, Nigeria. Sahel Medical Journal 2016, 19(1):16.

41. Chiang SC, Lee JK, Chen CH, Chuang LM, Tsan KW, Sheu WH, Wu DA, Wu TJ, Lin KC, Juang JH et al: Justifying the high prevalence of microalbuminuria for type 2 diabetic patients in Taiwan with conditional probability approach-a DEMAND II study. Journal of the Chinese Medical Association: JCMA 2011, 74(1):3-10.

42. Farahat TM, Elsaeed GK, Gazareen SS, Elsayed TI: Prevalence of proteinuria among type 2 diabetic patients in Menoufia governorate, Egypt. Menoufia Medical Journal2014, 27(2):363.

43. Vaidya S, Gupta B, Bhandari M, Behl S, Kosta S: Evaluate the relation between microalbuminuria and with other biochemical parameters related to complications of type 2 diabetes. International Journal of Advances in Medicine 2019, 6(5):1663.

44. Efundem NT, Assob JCN, Feteh VF, Choukem S-P: Prevalence and associations of microalbuminuria in proteinuria-negative patients with type 2 diabetes in two regional hospitals in Cameroon: a crosssectional study. BMC research notes 2017, 10(1):477.

45. Pallathodiyil RK: PREVALENCE OF MICROALBUMINURIA AND ASSOCIATED COMORBIDITIES IN DIABETIC PATIENTS-A HOSPITAL BASED STUDY FROM KERALA.

46. Habib M, Akbar N: Association of Microalbuminuria with HbA1c in Patients of Type II Diabetes Mellitus in Different Age Groups and Genders. Diabetes Case Rep 2018, 3(137):2.

47. Idowu AA, Ajose AO, Adedeji AT, Adegoke AO, Jimoh KA: Microalbuminuria, Other Markers of Nephropathy and Biochemical Derangements in Type 2 Diabetes Mellitus: Relationships and Determinants. Ghana medical journal 2017, 51(2):56-63.

48. Tepsukon C, O'Brien TE: Factors associated with microalbuminuria in type 2 diabetes patients in Nan Hospital, Thailand. Journal of Associated Medical Sciences 2014, 47(2):118-118.

\section{Figures}




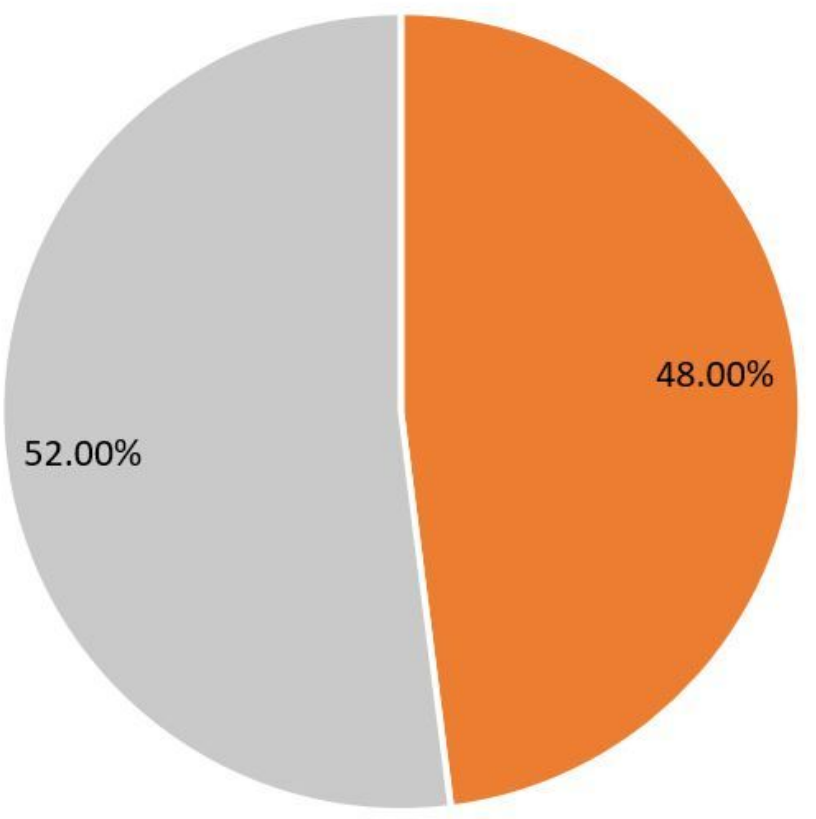

\section{keys \\ - Positive \\ - Negative}

\section{Figure 1}

Prevalence of microalbuminuria and Associated Factors among type 2 diabetes mellitus patients in Public Hospitals of Jigjiga town, Somali Region, Ethiopia, 2020. 